\title{
Advances in paediatric urology
}

David A Diamond, Ivy H Y Chan, Andrew J A Holland, Michael P Kurtz, Caleb Nelson, Carlos R Estrada Jr, Stuart Bauer, Paul K H Tam

Paediatric urological surgery is often required for managing congenital and acquired disorders of the genitourinary system. In this Series paper, we highlight advances in the surgical management of six paediatric urological disorders. The management of vesicoureteral reflux is evolving, with advocacy ranging from a less interventional assessment and antimicrobial prophylaxis to surgery including endoscopic injection of a bulking agent and minimally invasive ureteric reimplantation. Evidence supports early orchidopexy to improve fertility and reduce malignancy in boys with undescended testes. A variety of surgical techniques have been developed for hypospadias, with excellent outcomes for distal but not proximal hypospadias. Pelvi-ureteric junction obstruction is mostly detected prenatally; indications for surgery have been refined with evidence, and minimally invasive pyeloplasty is now standard. The outlook for patients with neurogenic bladder has been transformed by a combination of clean intermittent catheterisation, algorithms of diagnostic investigations, and innovative medical and surgical therapies. Posterior urethral valves are associated with considerable mortality; fetal diagnosis allows stratification of candidates for intervention, but ongoing bladder dysfunction in patients after valve ablation remains a cause of long-term morbidity.

Introduction

A substantial portion of paediatric urology entails surgical

correction of congenital and acquired disorders of the genitourinary system. With rapid developments in clinical and basic research, from prenatal diagnosis and minimally invasive surgery to evidence-based clinical guidelines, paediatric urology has become a major subspecialty. In this Series paper, we describe the exciting advances and innovations in the surgical management of six important paediatric urological disorders. Although minimally invasive surgery and innovative surgical techniques have improved early outcomes of common, non-lethal disorders such as vesicoureteral reflux, undescended testes, and the mild forms of hypospadias and pelvi-ureteric junction obstruction, most paediatric urological disorders, especially the severe anomalies, are associated with longterm morbidity. Treatment of neurogenic bladder exemplifies the advantages of a multidisciplinary approach with medical and innovative surgical therapies. Although fetal and neonatal diagnosis and treatment have improved survival in children with rare, complex, and life-threatening diseases such as posterior urethral valve, the management of long-term sequelae remain challenging.

\section{Vesicoureteral reflux}

Vesicoureteral reflux is the retrograde flow of urine from the bladder to the ureter (or ureters), affecting $1-25 \%$ of children and predisposing them to urinary tract infection and renal scarring. A comprehensive review is available elsewhere; here we focus on recent research findings. Although vesicoureteral reflux resolves in many cases, the ability to predict resolution in a given patient is limited. Vesicoureteral reflux grade is important. Multivariable models incorporating a range of factors, including vesicoureteral reflux index, 2 normograms, and ureteral diameter, might increase prognostic accuracy compared with vesicoureteral reflux grade alone, but the results for an individual patient can differ substantially between models, warranting caution in their clinical application.

Vesicoureteral reflux has a genetic basis, with concordance in identical twins approaching 100\%, and a 
27\% prevalence in siblings. 3 Although numerous genetic loci have been associated with vesicoureteral reflux, progress in identifying specific genetic targets for diagnosis or therapy is limited because of the heterogeneous genetic pattern. ${ }_{4}$ New genetic techniques are rapidly advancing discovery of human genetic contributors to congenital anomalies of the kidney and urinary tract, including vesicoureteral reflux. The UK' s National Institute for Health and Clinical Excellence and the American Academy of Pediatrics5 recommend a less interventional approach to assessing children with febrile urinary tract infection, with deferral of micturating cystourethrography until urinary tract infection recurrence. The rationale is to avoid overdiagnosis and overtreatment of indolent disease. One principle is that ultrasound serves as an initial

screen to identify children who should immediately proceed to further imaging by micturating cystourethrography, but there are limitations to using ultrasound to screen for vesicoureteral reflux, and a normal ultrasound does not exclude high-grade vesicoureteral reflux. ${ }_{6}$ Many specialists contest the conservative approach and warn that leaving vesicoureteral reflux undiagnosed puts a subset of children at increased risk of additional morbidity and potential renal damage associated with recurrent urinary tract infection.

When cystography is indicated, contrast-enhanced voiding sonography is increasingly seen as an alternative to fluoroscopic or radionuclide cystography. Results from several centres show comparable rates of detection of vesicoureteral reflux using this technique, , but the quality and completeness of information provided in reports varies, and some variation also can be seen in the same patient. Awareness of variations and standardisation is much needed. 8

The screening of asymptomatic siblings is controversial. According to guideliness released in 2010, screening of siblings is an option, but an observational approach could also be taken. In view of the relatively indolent nature of most sibling vesicoureteral reflux and the number of patients needed to screen to prevent adverse outcomes, the potential for benefits of screening siblings is low. 9

For the medical treatment of children with vesicoureteral reflux, data from the RIVUR ${ }_{10}$ randomised controlled trial showed that antimicrobial prophylaxis with trimethoprim plus sulfamethoxazole reduced the incidence of recurrent urinary tract infection by about $50 \%$ in children with vesicoureteral reflux or a history of vesicoureteral reflux. Findings from a subsequent metaanalysis $s_{11}$ confirmed a significant effect of antibiotic prophylaxis. Antibiotic prophylaxis has not been shown to reduce renal scarring, but no study has been adequately 
powered to assess this outcome. However, strong

evidence does suggest that a febrile urinary tract infection

is associated with risk of scarring, and early treatment of

febrile urinary tract infection can decrease the incidence.

Although open ureteral reimplantation is the gold

standard for surgery, many centres have pursued roboticassisted

laparoscopic reimplantation (figure 1). Adoption

has been limited because of concerns with higher

complication rates and lower success rates than for open

reimplantation, 12 although favourable results have been

reported from a series of robot-assisted procedures. 13

Pneumovesicoscopic

reimplantation (figure 2) has been

used as a minimally invasive alternative in several centres, ${ }_{14}$

and although the short-term results of open and

pneumovesical approaches were comparable, patients

undergoing pneurovesicoscopic ureteral reimplantation

had shorter hospital stays but longer operating times than

patients undergoing open ureteral reimplantation. Results

of a follow-up study confirmed satisfactory intermediate

outcomes of pneumovesical ureteric reimplantation. 15

Whether pneumovesicopic techniques will become more

widely adopted remains to be seen since the increasing use

of robotic-assisted transperitoneal approaches could limit

their uptake in affluent communities. Endoscopic therapy

(primarily with dextranomer hyaluronic acid copolymer;

figure 3) is a widely used alternative to surgical

reimplantation. In the Swedish reflux trial, ${ }_{16}$ antibiotic

prophylaxis and endoscopic treatment were superior to surveillance along in preventing recurrent urinary tract

infection. Endoscopic treatment is less invasive than

ureteric reimplantation but also has a lower success rate in correcting vesicoureteral reflux. ${ }_{17}$ Boys younger than

6 months with vesicoureteral reflux might benefit from

circumcision as this procedure is associated with a

ten-times reduction in the risk of urinary tract infection. 18

Undescended testes

Undescended testes is considered the most common

genital anomaly in boys, with a reported incidence that

varies between $0 \cdot 5 \%$ and $9 \%$ (1-5\% in most reports).

This variation reflects the clinical nature of the diagnosis, the patient population studied, and the inclusion or

otherwise of acquired undescended testes. 19 The apparent

increase in incidence suggested in some reports probably

reflects a combination of enhanced screening, improved

survival of premature infants, and strengthened

recognition of the ascending testis syndrome. 19

Ultrasound, although often used, has very little value in

the diagnosis and management of undescended testes.

Most cases appear congenital, but an important group of

cases present later in childhood, either as a result of

delayed diagnosis or development of ascending testis

syndrome in a previously descended testis ${ }_{19,20,21}$-hence

the importance of follow-up of boys with retractile testes. 
Bilateral, non-palpable testes at birth are rare and should prompt endocrinological and genetic assessment to exclude congenital adrenal hyperplasia or bilateral vanishing testes. A cases of acquired undescended testes occur as a result of postsurgical adhesions complicating inguinal surgery or reascent after orchidopexy. With increasing evidence that early surgery for undescended testes improves subsequent fertility (which is particularly impaired in men with bilateral undescended testes), reduces risk of torsion, has cosmetic advantages, and improves detection of any future malignancy, ${ }_{22}$ the American Urological Association and the European Association of Urology advocate orchidopexy at 6-18 months of age. ${ }_{23,24}$ Unfortunately, many boys are still not having early surgery, 25 and awareness of the need for early referral and timely surgical intervention should be improved (figure 4). Fertility is typically assessed with surrogate markers such as testicular volume, testicular histology, and semen analysis. 26,27 In one study, 26 normal sperm counts were reported in $96 \%$ of patients who had surgical treatment before 1 year of age, compared with $75 \%$ of patients who had surgery when aged 1-2 years. Hormonal treatment is controversial but might have a role in selected cases with a high risk of infertility. 28 The testes undergo a critical phase of development in the first 6 months of life, with selected gonocytes transforming into adult dark-spermatogonia for future spermatogenesis and non-transforming gonocytes undergoing apoptosis. 29 Adult dark-spermatogonia seem to be crucial determinants of future sperm counts and potential fertility. 27 Although the overall risk of malignancy in adult men who had early surgery for undescended testes is $1 \cdot 6-7 \cdot 5$ times the baseline prevalence, this prevalence is known to increase 2 -9-32 times in men who had surgery when they were older than 10 years. 22,30,31 Persistent non-transforming gonocytes might be the originating cells of testicular malignancies in men with undescended testes. To enhance fertility and reduce malignancy, there is an argument for even earlier surgery at 3 months of age, but this option must be assessed in long-term studies. Most boys with palpable undescended testes will have an open, inguinal orchidopexy, with the testes placed in a scrotal, subdartos pouch. Minimally invasive surgery is appropriate for boys with impalpable undescended testes, and parascrotal incision is used for low undescended testes. Outcomes from these different approaches will depend on the initial position of the testis, the mobility and length of the testicular vessels, surgery has transformed the ability to assess and manage impalpable or intra-abdominal undescended testes. The traditional Fowler-Stephens staged orchidopexy, with initial division of the testicular vessels to stimulate 
collateral circulation through gubernacular vessels and the artery to the vas, followed by a delayed second-stage orchidopexy, could be readily performed laparoscopically as a day-case procedure, with reported atrophy of $2-33 \%$. 32 With outcomes now equivalent to those of testicular autotransplantation, attention has moved to the possibility of a one-stage procedure. ${ }_{33}$ Establishing equivalence of orchidopexy outcomes remains very difficult without consistent, objective assessment of initial testicular position and its mobility at the time of surgery. 19,22

\section{Hypospadias}

The incidence of hypospadias (1/300 newborn boys) was once thought to be increasing, with a doubling of incidence in the USA in the 1970s and 1980s. However, European and Australian data have indicated a more stable incidence in the past 10 years. ${ }_{34,35}$ The data reported worldwide remain conflicting, and reported incidence ranges from $0 \cdot 6$ to $34 \cdot 2$ per 10000 live births. 36 Increasing awareness of the disease, putative effects from environmental endocrine disruptors, and differing study methodologies might all have contributed to the variations in reported incidence.

The aetiology of hypospadias seems to be multifactorial. Genetic anomalies are likely to be important, but most mutations have been identified comparatively infrequently and typically in the most severe or syndromal cases. Distal hypospadias, the most common type, is probably polygenic or multifactorial. ${ }_{37}$ Limited epidemiological evidence $_{38}$ suggests a small increased risk with prenatal and postnatal exposure to environment-disrupting chemicals such as pesticides, cosmetics, industrial chemicals, and some medications. In a systematic review from 2012, ${ }_{37}$ low birthweight, maternal hypertension, and pre-eclampsia were consistently implicated in hypospadias.

Surgical repair aims to reconstruct the urethra, correct chordee, and improve cosmesis with minimal morbidity. Many techniques have been described, but no clear single best method of urethroplasty has been identified. Choice of method largely depends on a comparatively subjective appraisal of the patient' $s$ anomalous anatomy (including location of the urethral meatus and severity of chordee) and the surgeon' $s$ experience and preference. 39,40 Repair might take a one-stage or two-stage approach, using the patient' $s$ own preputial skin for reconstruction in most cases. Other tissues used in reconstruction include buccal mucosa, tunica vaginalis flap, scrotal skin, and bladder or tongue mucosa.

The single-stage tubularised incised plate method, first described by Snodgrass39 and with complication rates

of $7 \%$ and $11 \%$ in distal and proximal hypospadias, respectively, is an effective and popular option, especially for distal hypospadias. In a 2012 systematic review, ${ }_{41}$ 
tubularised incised plate and Mathieu (meatal-based flap) methods (figure 5) for repair of distal hypospadias were compared; although the complication rates of both procedures were low, repair by the tubularised incised plate method was associated with the lowest incidence of urethra-cutaneous fistula, whereas Mathieu repair had the lowest rate of meatal stenosis.

Preference of repair method for proximal hypospadias varies, but staged urethroplasty is preferred by nearly half of surgeons, particularly in the presence of severe chordee. Other common techniques include the extended tubularised incised plate method, with or without a graft, or an onlay procedure. Irrespective of the method, surgical repair of proximal hypospadias remains challenging: in one referral centre with a large patient volume, reoperation was required in up to $50 \%$ of patients, with urethro-cutaneous fistulas occurring in up to $30 \%$ of cases. ${ }_{42}$ Operative complications are reduced substantially with increasing surgical experience. 43 Operations for hypospadias are usually done within the first 2 years of life. Parents commonly ask about long-term function and future fertility. Outcome remains difficult to measure objectively, with changing surgical techniques in the past 30-40 years and inadequate data on long-term follow-up. Patients with distal hypospadias generally have low complication rates, with acceptable long-term functional and cosmetic outcomes. In a systematic review of long-term outcomes, ${ }_{44}$ lower urinary tract symptoms such as a weak stream, dribbling, or spraying were twice as common in adult men who had hypospadias repair than in the control group. In a 2009 study, ${ }_{45}$ semen quality did not differ between men with isolated hypospadias and men in a control group, yet the paternity rate was lower $(24 \%)$ in men who had surgery for hypospadias than the general age-matched population (29\%). Paternity and sexual function might be related to psychosexual development, and this seems to particularly affect boys with proximal hypospadias. More patients with hypospadias (33\%) than in a general population (13\%) reported an inhibition in seeking sexual contact. ${ }_{46}$ Patients with severe hypospadias remain much less satisfied with penile appearance than patients with hypospadias in general or controls. ${ }_{44}$ For the subset of patients with severe hypospadias, objective, validated assessment and good

understanding of long-term outcome and function in adult life.

\section{Pelvi-ureteric junction obstruction}

Antenatal hydronephrosis is found in up to $4 \cdot 5 \%$ of all pregnancies, making it one of the most common urological abnormalities. Non-operative management will fail in about a third of patients with high-grade hydronephrosis (Society for Fetal Urology grade 3-4) due to pelvi-ureteric or ureteropelvic junction obstruction, and the anterior-posterior diameter of the renal pelvis 
appears to be the strongest predictor of the need for intervention postnatally. ${ }_{47}$ Various cutoffs have been proposed, ranging from $16 \mathrm{~mm}_{48}$ to $24 \mathrm{~mm}$, ${ }_{47}$ with variable sensitivity and specificity. Conservative management for high-grade hydronephrosis even in the first 12 months of age can be associated with some loss of renal function. ${ }_{49}$ New schematics in classifying antenatal hydronephrosis by ultrasound, such as the upper tract dilation system, have been proposed. In some studies, the upper tract dilation system could not discriminate operative from non-operative candidates, 50 whereas in other studies, the upper tract dilation system has been found to be more predictive. 51

The costs associated with imaging in terms of discomfort, time spent by the patient and family, and radiation exposure in nuclear renography creates a tremendous opportunity for urinary biomarkers in a diagnostic algorithm to select the patients needing surgical correction. Urinary concentration of molecular markers for kidney injury or adhesion, growth factors, and cytokines have been used in studies, but issues with the heterogeneous timing of assessment and sample size limit their applicability as predictive markers. ${ }_{2}$ An unbiased examination of the urinary proteome will yield even more information from a broad sample of patients; for example, a screen of 1100 urinary proteins yielded 76 candidate proteins with diverse functions in inflammation, kidney cell adhesion, leucocyte migration, vasculogenesis, and carbohydrate metabolism. 53 Further studies could earn such a panel of biomarkers a place in a diagnostic algorithm. Functional magnetic resonance urography is a radiation-free way of assessing renal function, and although this technology offers an excellent $5 \%$ intraobserver and interobserver variability, issues of variability seem to be magnified in the infant population. 54 Beyond infancy, minimally invasive surgery for pelviureteric junction repair (figure 6) is becoming increasingly popular, especially in school-aged children. 55 A definitive benefit of laparoscopy compared with traditional open repairs in terms of cost, reduction in complication, or shortened hospital stay has been difficult to demonstrate, and results of a single-centre randomised trial ${ }_{56}$ showed clinical equivalence between the two methods, with the disadvantage of a 17 min longer operative time in the minimally invasive group $(\mathrm{p}<0 \cdot 01)$ offset by the advantage of a $2 \cdot 3 \mathrm{~h}$ shorter hospital stay $(\mathrm{p}=0 \cdot 02)$. Outcomes described in singlecentre reports remain heterogeneous, especially for laparoscopy procedures, without details such as whether the Anderson-Hynes dismemberment was accomplished or other forms of plastic operations on the pelvi-ureteric junction were employed. However, even for the failed pyeloplasty, minimally invasive revision is safe and potentially more efficacious than open repair. ${ }_{57}$ The simple surgical displacement of a crossing vessel, which 
avoids a sutured anastomosis, is an attractive laparoscopic

option that has been successful in some cases58 but

carries the risk of leaving intrinsic obstruction

unrelieved. 59

In affluent communities, robotic assistance is more

common than laparoscopy alone, perhaps because of

ease of suturing. The standard transperitoneal robotic

approach leaves a well hidden umbilical scar, an

ipsilateral lower quadrant scar, and a epigastric scar that

can be cosmetically troublesome. An alternative robotic

approach leaves an umbilical scar and two lower quadrant incisions at the level of a Pfannenstiel incision, which patients have been shown to prefer. ${ }_{60}$ Further efforts are being made by surgeons to decrease surgical scars with conventional and robotic single-incision pyeloplasty. 61,62 Infants will qualify for a standard robotic procedure when they have a pubis-to-xyphoid distance of more than $15 \mathrm{~cm}$, which is generally reached by 6 months of age if full term. 63

\section{Neurogenic bladder}

Neurogenic bladder affects $1 \cdot 5-2$ babies per 10000 livebirths. The challenge for the paediatric surgical specialist is to protect renal function and achieve urinary continence. The most common cause of paediatric neurogenic bladder is spina bifida. Other congenital

causes include caudal regression and anorectal malformations. Acquired causes include spinal cord injury (trauma, infection, or tumour), extensive pelvic surgery, or CNS insults. ${ }_{64}$ Renal failure was once the most common cause of death in young adults with spina bifida, but modern management has transformed the long-term outlook, although many challenges remain. No consensus guidelines exist for the management of paediatric neurogenic bladder. In 2012, the International Children's Continence Society provided recommendations 65 for the management of neurogenic bladder

in children, and the US Centers for Disease Control and Prevention (CDC) convened an expert group to develop protocolised management. ${ }_{66}$ Patient recruitment began in 2015, and results are expected by 2020. This effort is in direct response to the known and substantial variability in the management of these patients. ${ }_{77}$ Although a more conservative policy exists, the following recommendations are illustrative of a proactive approach based on the belief that renal and bladder deterioration relies can be prevented with close and consistent follow-up. Early urodynamic studies and, if indicated, clean intermittent catheterisation and anticholinergic therapy, are protective against renal deterioration. External urethral sphincter function determines whether a patient' s bladder and sphincter are synergic or dyssynergic and therefore whether the patient is at risk of renal deterioration. Since this status is most likely to change in the first few years of life, patients should 
undergo urodynamic studies every 6 months during the

first 2 years of life, yearly when aged 2-5 years, and on an individualised basis thereafter. An ultrasound of the kidneys and bladder is obtained at least on a yearly basis, with emphasis on renal anatomy. Data from urodynamic studies suggest that bladder wall thickness has little association with bladder function, emphasising the absence of alternatives to invasive testing. 68 A micturating cystourethrogram should be obtained in infants with dyssynergy or upper urinary tract dilation if video urodynamic study facilities and capability are not available. Finally, the CDC protocol recommends a dimercaptosuccinic acid scan at 3 months and 5 years of age to assess for renal scarring. 65

Prenatal closure of spina bifida has recently been described and is being done in a limited number of centres in the USA. 69 Initial findings suggest reduced rates of ventriculoperitoneal shunting and improved ambulation. Some data suggest that bladder function in patients who have prenatal closure might not be different from patients closed postnatally, zo but further follow-up is needed.

The mainstay of medical management of neurogenic bladder is anticholinergic therapy. ${ }^{11}$ Oxybutynin chloride is the most widely used anticholinergic and is effective in neurogenic bladder treatment by increasing capacity, lowering urinary storage pressures, and abolishing overactive contractions. 2 Alternative options for patients with overactive bladder contractions who are intolerant or refractory to anticholinergic therapy include mirabegron, a $\beta 3$-adrenoceptor agonist, and gabapentin. If urodynamic studies reveal inadequate urethral resistance, $\alpha$-sympathomimetic agents are added. There is often close association between bladder and bowel dysfunctions so an effective bowel-management programme for constipation and faecal incontinence should also be in place. Surgical options must be considered when medical management has failed. ${ }_{73}$ Classically, bladder augmentation by enterocystoplasty is definitive, but this method causes substantial short-term and long-term complications. In the rare case where a patient has a grossly dilated ureter associated with a non-functioning or minimally functioning kidney, a ureterocystoplasty can be considered, in either an open or laparoscopic manner. ${ }^{4}$ This technique eliminates several risks associated with enterocystoplasty. 75 The use of botulinum toxin injected endoscopically into the bladder is an alternative option. ${ }_{6}$ Patient selection for botulinum therapy seems to be crucial; although effective in improving overactive contractions, botulinum therapy is ineffective in the management of fibrotic, poorly compliant bladders. 76

Tissue engineering has the potential to provide off-theshelf tissues for reconstructive surgery. To date, pioneering techniques that showed short-term efficacy 
have failed to show long-term success, 77,78 but intensive efforts to develop reliable tissue engineering-based options continue and are promising.

In patients for whom intermittent catheterisation via urethra is difficult or impossible, a continent catheterisable channel using appendix, reconfigured bowel, or ureter is an important tool in the paediatric surgeon' s armamentarium. 79

Treating sphincter weakness incontinence continues to be challenging; the effectiveness of bladder outlet procedures is highly variable, and when done without augmentation, cystoplasty might expose the upper tracts to increased pressures and lead to adverse outcome. 80 0verall, the way children with neurogenic bladder are managed has improved dramatically in the past 40 years. An astounding number of patients now live into adulthood. This advance has been made possible by close follow-up, the advent of clean intermittent catheterisation, reliable urodynamic studies, drugs that modulate bladder function, and surgical techniques that have been promoted and refined in the past few decades.

\section{Posterior urethral valves}

With an incidence of about $1 / 5000$ newborn boys, posterior urethral valves are the most common cause of congenital lower urinary tract obstruction (LUTO). Posterior urethral valves are associated with high fetal and neonatal mortality (30\%) and considerable lifelong morbidity. In severe cases, the disorder can lead to anhydramnios and pulmonary dysplasia during the

canalicular phase of lung development. Abnormal renal development persists into childhood and adolescence: $30-42 \%$ of patients develop end-stage renal failure, making posterior urethral valves the most common cause for paediatric renal transplantation. Some patients will develop bladder dysfunction.

Recent advances in treatment concern fetal diagnosis and management. LUTO is increasingly recognised as a spectrum of diseases, and candidacy for fetal intervention varies accordingly. ${ }_{81}$ Patients with stage I disease (mild) present with normal amniotic fluid volume and fetal kidneys that are normal in echogenicity; no intervention is necessary at this stage. At the other end of the spectrum, patients with stage III disease (severe) present with oligohydramnios or anhydramnios and signs of abnormal fetal renal function (ie, renal dysplasia, cortical cysts, unfavourable fetal urinary biochemistry); intervention at this stage is controversial. Patients with stage II disease (severe) present with oligohydramnios or anhydramnios and severe bilateral hydronephrosis, but fetal renal function might be preserved (ie, no renal cysts or dysplasia, and favourable fetal urine biochemistry); experts suggest intervention and shunting at this stage could double the odds of survival. 82 Intervention has traditionally taken the form of 
vesicoamniotic shunting, percutaneously placing a

double-coiled plastic tube with one coil in the fetal bladder and the other in the amniotic space. Little has changed in shunt design since the 1980s, and clogging or shunt dislodgement cause problems leading to the need for recurrent intervention, with risks of rupture of membranes assumed each time. 83 Outcomes of a large trial ${ }_{82}$ suggest a $30 \%$ device-related complication rate. There was initial enthusiasm for fetoscopic ablation of posterior urethral valves because it addressed the problem definitively without issues of dislodgment. Although fetal cystoscopy is accurate for diagnosis, its therapeutic effectiveness compared with shunting has not been proven. ${ }_{84}$ Therapeutic fetoscopy is not applicable for all causes of LUTO (ie, urethral atresia), and fetal valve ablation risks urethral and adjacent organ injury 85 because laser energy can travel posteriorly. Bypassing the fetus entirely, serial amnioinfusion to restore amniotic fluid volume, either percutaneously or with an infusion port, has been proposed. This procedure has been successful technically but is still at an early stage of study. 86

Postnatally, it is crucial to determine precisely the cause of bladder-outlet obstruction. Ultrasound and fluoroscopic micturating cystourethrography are standard diagnostic investigations, although their performance characteristics are currently unassessable. 87 Just as in vesicoureteral reflux, ultrasound-based contrast agents have the potential to supplant fluoroscopic studies. Findings in early reports suggested that an ultrasound probe placed on the perineum and traditional micturating cystourethrography had similar sensitivity and specificity in detecting urethral anomalies. 88 Some infants might have dysplastic kidneys, and nuclear studies could prove useful, but rarely before 2 months of age. Notably, while the pop-off mechanism of unilateral vesicoureteral reflux has traditionally been thought to protect the contralateral renal unit from high pressure, more recent findings call this into question. 89 In a full-term baby, the standard of care for posterior urethral valves is circumcision to reduce the risk of infection and cystoscopic valve ablation. Hook cautery, cold knife, and laser energygo are all effective. Adequacy of valve ablation might be difficult to assess initially as dilation often persists; a ratio of $2 \cdot 5: 1$ or less between the width of the mid-posterior urethra on oblique fluoroscopic film and the maximum diameter of the bulbar urethra often indicates successful ablation. ${ }_{91} \mathrm{~A}$ high level of suspicion should remain for stricture or residual posterior urethral valves if bladder emptying is poor. Even withstanding a normal micturating cystourethrograph, cystosopy might reveal remnants of valves in up to $50 \%$ of patients. 92 In infants with extremely low birthweight, the urethra 
might be too small to admit cystoscopic equipment

safely. Long-term catheter drainage is inadvisable

because of the risk of candidaemia. Rather than risking

stricture with cystoscopic instrumentation, these babies should either undergo open vesicostomy or the rarely used but effective Fogarty balloon valve ablation under fluoroscopic guidance. 93

Notwithstanding surgical relief of urethral obstruction, ongoing bladder dysfunction is both a cause of morbidity and potential threat to upper tract function. Up to $80 \%$ of vesicoureteral reflux will resolve after valve ablation. ${ }_{94} \mathrm{~A}$ small, contracted bladder in infancy that progresses to a large-capacity, poorly compliant bladder, often found in the presence of persistent upper tract dilation and nephrogenic diabetes insipidus, has been termed valve bladder. ${ }_{95,96}$ This can create a self-injurious cycle, with persistent dilation leading to a worsening renal

concentrating defect and creating more work for a bladder at risk of muscular failure. Regular urodynamic monitoring is crucial in the management of these patients.

\section{Discussion}

Advances in paediatric urology have been remarkable, especially because innovations and randomised controlled trials are difficult to implement in the paediatric population and because diseases are heterogeneous. In the coming years, refinements in fetal diagnosis and interventions and the introduction of regenerative medicine and tissue engineering for bladder reconstruction can be anticipated. The benefits of minimally invasive surgery and robot-assisted surgery compared with conventional surgery and non-operative treatments needs to be defined through large, multicentre, randomised controlled trials. The importance of a smooth

transition of care from paediatric urology to adult urology cannot be overemphasised. Many challenges remain, but research and innovations will be rewarding as the benefits for patients will be lifelong.

\section{Contributors}

PKHT wrote the summary, introduction, and conclusion. AJAH and IHYC wrote the sections about undescended testes and hypospadias. MPK and DAD wrote the sections about pelvi-ureteric junction obstruction and posterior urethral valves. CRE, SB, and DAD wrote the section about neurogenic bladder. CN, IHYC, and DAD wrote the section about vesicoureteral reflux. PKHT critically reviewed and redrafted the whole report. All authors approved the final version of the report for publication.

Declaration of interests

We declare no competing interests.

References

1 Tullus K. Vesicoureteric reflux in children. Lancet 2015; 385: 371-79.

2 Kirsch AJ, Arlen AM, Leong T, et al. Vesicoureteral reflux index (VURx): a novel tool to predict primary reflux improvement and resolution in children less than 2 years of age. J Pediatr Urol 2014; 10: $1249-54$.

3 Skoog SJ, Peters CA, Arant BS Jr, et al. Pediatric vesicoureteral reflux guidelines panel summary report: clinical practice guidelines for screening siblings of children with vesicoureteral reflux and neonates/ infants with prenatal hydronephrosis. J Urol 2010; 184: 1145-51. 
4 Nino F, Ilari M, Noviello C, et al. Genetics of vesicoureteral reflux. Curr Genomics 2016; 17: 70-79.

5 Subcommittee on Urinary Tract Infection, Steering Committee on Quality Improvement and Management. Urinary tract infection: clinical practice guideline for the diagnosis and management of the initial UTI in febrile infants and children 2 to 24 months. Pediatrics 2011; 128: 595-610.

6 Nelson CP, Johnson EK, Logvinenko T, Chow JS. Ultrasound as a screening test for genitourinary anomalies in children with UTI. Pediatrics 2014; 133: e394-403.

7 Wozniak MM, Wieczorek AP, Pawelec A, et al. Two-dimensional (2D), three-dimensional static (3D) and real-time (4D) contrast enhanced voiding urosonography (ceVUS) versus voiding cystourethrography (VCUG) in children with vesicoureteral reflux. Eur J Radiol 2016; 85: 1238-45.

8 Frimberger D, Bauer SB, Cain MP, et al. Establishing a standard protocol for the voiding cystourethrography. J Pediatr Urol 2016; 12: $362-66$.

9 Nelson CP, Finkelstein JA, Logvinenko T, Schuster MA.

Incidence of urinary tract infection among siblings of children with vesicoureteral reflux. Acad Pediatr 2016; 16: 489-95.

10 RIVUR Trial Investigators, Hoberman A, Greenfield SP, et al. Antimicrobial prophylaxis for children with vesicoureteral reflux. N Engl J Med 2014; 370: 2367-76.

11 Wang HH, Gbadegesin RA, Foreman JW, et al. Efficacy of antibiotic prophylaxis in children with vesicoureteral reflux: systematic review and meta-analysis. J Urol 2015; 193: 963-69.

12 Kurtz MP, Leow JJ, Varda BK, et al. Robotic versus open pediatric ureteral reimplantation: costs and complications from a nationwide sample. J Pediatr Urol 2016; 12: 408 e1-6.

13 Akhavan A, Avery D, Lendvay TS. Robot-assisted extravesical ureteral reimplantation: outcomes and conclusions from 78 ureters. J Pediatr Urol 2014; 10: 864-68.

14 Chung PHY, Tang DYY, Wong KKY, et al. Comparing open and pneumovesical approach for ureteric reimplantation in pediatric patients-a preliminary review. J Pediatr Surg 2008; 43: 2246-49. 15 Lau CT, Lan LC, Wong KK, Tam PK. Pneumovesical ureteric reimplantation in pediatric patients: an intermediate term result. J Laparoendosc Adv Surg Tech A 2017； 27: 203-05.

16 Brandstrom P, Esbjorner E, Herthelius M, Swekersson S, Jodal U, Hansson S. The Swedish reflux trial in children: III. Urinary tract infection pattern. J Urol 2010; 184: 286-91.

17 Yap TL, Chen Y, Nah SA, Ong CC, Jacobsen A, Low Y.

STING versus HIT technique of endoscopic treatment for vesicoureteral reflux: a systematic review and meta-analysis. J Pediatr Surg 2016; 51: 2015-20.

18 Singh-Grewal D, Macdessi J, Craig J. Circumcision for the prevention of urinary tract infection in boys: a systematic review of randomised trials and observational studies. Arch Dis Child 2005; 90: $853-58$.

19 Holland AJA, Nassar N, Schneuer FJ. Undescended testes: an update. Curr Opin Pediatr 2016; 28: 388-94.

20 Hutson JM, Thorup J. Evaluation and management of the infant with cryptorchidism. Curr Opin Pediatr 2015; 26: 520-24.

21 Snodgrass W, Bush N, Holzer M, Zhang S. Current referral patterns and means to improve accuracy in diagnosis of undescended testis. Pediatrics 2011; 127: e382-88.

22 Chan E, Wayne C, Nasr A. Ideal timing of orchiopexy: a systematic review. Pediatr Surg Int 2014; 30: 87-97.

23 Kolon TF, Herndon CD, Baker LA, et al. Evaluation and treatment of cryptorchidism: AUA guideline. J Urol 2014; 192: 337-45. 24 Radmayr C, Dogan HS, Hoebeke P, et al. Management of undescended testes: European Association of Urology/European Society for Paediatric Urology guidelines. J Pediatr Urol 2016; 12: $335-43$.

25 Schneuer FJ, Holland AJ, Pereira G, Jamieson S, Bower C, Nassar N. Age at surgery and outcomes of an undescended testis. Pediatrics 2016; 137: e20152768.

26 Feyles F, Peiretti V, Mussa A, et al. Improved sperm count and motility in young men surgically treated for cryptorchidism in the first year of life. Eur J Pediatr Surg 2014; 24: 376-80. 
27 Kraft KH, Canning DA, Snyder HM 3rd, Kolon TF.

Undescended testis histology correlation with adult hormone levels

and semen analysis. J Urol 2012; 188 (4 supp1): 1429-35.

28 Chua ME, Mendoza JS, Gaston MJ, Luna SL, Morales ML.

Hormonal therapy using gonadotropin releasing hormone for

improvement of fertility index among children with cryptorchidism:

a meta-analysis and systematic review. J Pediatr Surg 2014;

49: 1659-67.

29 Hutson JM, Southwell BR, Li R, et al. The regulation of testicular descent and the effects of cryptorchidism. Endocr Rev 2013;

34: 725-52.

30 Lip SZ, Murchison LE, Cullis PS, Govan L, Carachi R. A meta-analysis

of the risk of boys with isolated cryptorchidism developing testicular cancer in later life. Arch Dis Child 2013; 98: 20-26.

31 Pettersson A, Richiardi L, Nordenskjoid A, Kaijser M, Akre 0.

Age at surgery for undescended testis and risk of testicular cancer.

N Engl J Med 2007; 356: 1835-41.

32 Wayne C, Chan E, Nasr A, Canadian Association of Paediatric

Surgeons. Evidence-Based Resource. What is the ideal surgical

approach for intra-abdominal testes? A systematic review.

Pediatr Surg Int 2015; 31: 327-38.

33 0stlie DJ, Leys CM, Fraser JD, Snyder CL, St Peter SD.

Laparoscopic orchiopexy requiring vascular division: a randomized

study comparing the primary and two-stage approaches.

J Laparoendosc Adv Surg Tech A 2015; 25: 536-39.

34 Bergman JE, Loane M, Vrijheid M, et al. Epidemiology of

hypospadias in Europe: a registry-based study. World J Urol 2015;

33: $2159-67$.

35 Schneuer FJ, Holland AJ, Pereira G, Bower C, Nassar N.

Prevalence, repairs and complications of hypospadias: an Australian population-based study. Arch Dis Child 2015; 100: 1038-43.

36 Springer A, van den Heijkant M, Baumann S. Worldwide prevalence of hypospadias. J Pediatr Urol 2016; 12: 152. e1-7.

37 van der Zanden LF, van Rooij IA, Feitz WF, Franke B, Knoers NV,

Roeleveld N. Aetiology of hypospadias: a systematic review of genes and environment. Hum Reprod Update 2012; 18: 260-83.

38 Bonde JP, Flachs EM, Rimborg S, et al. The epidemiologic evidence linking prenatal and postnatal exposure to endocrine disrupting chemicals with male reproductive disorders: a systematic review and meta-analysis. Hum Reprod Update 2016; 23: 104-25.

39 Snodgrass W, Bush N. Primary hypospadias repair techniques:

a review of the evidence. Urol Ann 2016; 8: 403-08.

40 Springer A, Tekgul S, Subramaniam R. An update of current

practice in hypospadias surgery. Eur Urol Supplements 2017;

16: $8-15$.

41 Wilkinson DJ, Farrelly P, Kenny SE. Outcomes in distal

hypospadias: a systematic review of the Mathieu and tubularized

incised plate repairs. J Pediatr Urol 2012; 8: 307-12

42 Pippi Salle JL, Sayed S, Salle A, et al. Proximal hypospadias: a persistent challenge. Single institution outcome analysis of three surgical techniques over a 10-year period. J Pediatr Urol 2016; 12: 28. e1-7.

43 Horowitz M, Salzhauer E. The 'learning curve' in hypospadias surgery. BJU International 2006; 97: 593-96.

44 Rynja SP, de Jong T, Bosch J, de Kort LMO. Functional, cosmetic and psychosexual results in adult men who underwent hypospadias correction in childhood. J Pediatr Urol 2011; 7: 504-15.

45 Asklund C, Jensen TK, Main KM, Sobotka T, Skakkebaek NE, Jorgensen N. Semen quality, reproductive hormones and fertility of men operated for hypospadias. Int J Androl 2010; 33: 80-87.

46 Mureau MAM, Slijper FME, van der Meulen JC, Verhulst FC, Slob KA. Psychosexual adjustment of men who underwent hypospadias repair: norm-related study. J Urol 1995; 154: 1351-55. 47 Arora S, Yadav P, Kumar M, et al. Predictors for the need of surgery in antenatally redetected hydronephrosis due to UPJ obstruction-a prospective multivariate analysis. J Pediatr Urol 2015; 11: 248. e1-5.

48 Dias CS, Silva JM, Pereira AK, et al. Diagnostic accuracy of renal pelvic dilatation for detecting surgically managed ureteropelvic junction obstruction. J Urol 2013; 190: 661-66. 
49 Babu R, Rathish VR, Sai V. Functional outcomes of early versus delayed pyeloplasty in prenatally diagnosed pelvi-ureteric junction obstruction. J Pediatr Urol 2015; 11: 63. e1-5.

50 Rickard M, Easterbrook B, Kim S, et al. Six of one, half a dozen of the other: a measure of multidisciplinary inter/intra-rater reliability of the society for fetal urology and urinary tract dilation grading systems for hydronephrosis. J Pediatr Urol 2017;

13: 80 . e1-5.

51 Chalmers DJ, Meyers ML, Brodie KE, Palmer C, Campbell JB. Inter-rater reliability of the APD, SFU and UTD grading systems in fetal sonography and MRI. J Pediatr Urol 2016; 12: 305. e1-5. 52 Chevalier RL. Prognostic factors and biomarkers of congenital obstructive nephropathy. Pediatric Nephrology 2016; 31: 1411-20. 53 Froehlich JW, Kostel SA, Cho PS, et al. Urinary proteomics yield pathological insights for ureteropelvic junction obstruction. Mol Cell Proteomics 2016; 15: 2607-15.

54 Khrichenko D, Saul D, Adeb M, et al. Intra- and inter-observer variability of functional MR urography (fMRU) assessment in children. Pediatr Radiol 2016; 46: 666-73.

55 Varda BK, Johnson EK, Clark C, Chung BI, Nelson CP, Chang SL. National trends of perioperative outcomes and costs for open, laparoscopic and robotic pediatric pyeloplasty. J Urol 2014; 191: 1090-95.

56 Gatti JM, Amstutz SP, Bowlin PR, Stephany HA, Murphy JP. Laparoscopic vs open pyeloplasty in children: results of a randomized, prospective, controlled trial. J Urol 2017; 197: 792-97. 57 Leung L, Chan IH, Chung PH, Lan LC, Wong KK, Tam PK. Outcomes of re-intervention for laparoscopic transperitoneal pyeloplasty in children. J Laparoendosc Adv Surg Tech A 2016; 26: 318-23.

58 Esposito C, Bleve C, Escolino M, et al. Laparoscopic transposition of lower pole crossing vessels (vascular hitch) in children with pelviureteric junction obstruction. Transl Pediatr 2016; 5: 256-61. 59 Menon P, Rao KL, Sodhi KS, Bhattacharya A, Saxena AK, Mittal BR. Hydronephrosis: comparison of extrinsic vessel versus intrinsic ureteropelvic junction obstruction groups and a plea against the vascular hitch procedure. J Pediatr Urol 2015; 11: 80. e1-6.

60 Gargollo PC. Hidden incision endoscopic surgery: description of technique, parental satisfaction and applications. J Urol 2011; 185: $1425-31$

61 Bi Y, Lu L, Ruan S. Using conventional 3- and 5-mm straight instruments in laparoendoscopic single-site pyeloplasty in children. J Laparoendosc Adv Surg Tech A 2011；21: 969-72.

62 Law J, Rowe N, Archambault J, Nastis S, Sener A, Luke PP.

First Canadian experience with robotic single-incision pyeloplasty: comparison with multi-incision technique. Can Urol Assoc J 2016; 10: $83-88$.

63 Finkelstein JB, Levy AC, Silva MV, Murray L, Delaney C, Casale P. How to decide which infant can have robotic surgery? Just do the math. J Pediatr Urol 2015; 11: 170. e1-4.

64 Sturm RM, Cheng EY. The management of the pediatric neurogenic bladder. Curr Bladder Dysfunct Rep 2016; 11: 225-33. 65 Bauer SB, Austin PF, Rawashdeh YF, et al. International Children's Continence Society' s recommendations for initial diagnostic evaluation and follow-up of congenital neuropathic bladder and bowel dysfunction in children. Neurourol Urodynam 2012; 31: 610-14. 66 Routh JC, Cheng EY, Austin JC, et al. Design and methodological considerations of the Centers for Disease Control and prevention urological and renal protocol for the newborn and young child with spina bifida. J Urol 2016; 196: 1728-34.

67 Lodwick D, Asti L, Deans K, Minneci P, McLeod D. Variation in practice patterns for the management of newborn spina bifida patients in the United States. Urology 2017; 100: 207-12.

68 Kim WJ, Shiroyanagi Y, Yamazaki Y. Can bladder wall thickness predict videourodynamic findings in children with spina bifida? J Urol 2015; 194: 180-83.

69 Adzick NS, Thom EA, Spong CY, et al. A randomized trial of prenatal versus postnatal repair of myelomeningocele. N Engl J Med 2011; 364: 993-1004.

70 Brock JW 3rd, Carr MC, Adzick NS, et al. Bladder function after fetal surgery for myelomeningocele. Pediatrics 2015; 136: e906-13.

71 Austin P, Bauer SB. Medical management of the neurogenic 
bladder. In: Franco I, Austin P, Bauer S, von Gontard A, Homsy Y, eds. Pediatric incontinence. West Sussex, UK: John Wiley \& Sons, 2015: 263-72.

72 Baek M, Kang JY, Jeong J, Kim DK, Kim KM. Treatment outcomes according to neuropathic bladder sphincter dysfunction type after treatment of oxybutynin chloride in children with myelodysplasia. Int Urol Nephrol 2013; 45: 703-09.

73 Rawashdeh YF, Austin P, Siggaard C, et al. International Children's Continence Society' s recommendations for therapeutic intervention in congenital neuropathic bladder and bowel dysfunction in children. Neurourol Urodynam 2012; 31: 615-20.

74 Landa Juarez S, Fernandez AM, Castro NR, De La Cruz Yanez H, Hemandez CG. Laparoscopic ureterocystoplasty with Mitrofanoff system. J Laparoendosc Adv Surg Tech A 2014; 24: 422-27.

75 0zdemir T, Arikan A. Ureterocystoplasty in pediatric patients with unilateral non-functioning kidney. Turk J Urol 2013; 39: 232-36.

76 Scheepe JR, Blok BF, 't Hoen LA. Applicability of botulinum toxin type A in paediatric neurogenic bladder management.

Curr Opin Urol 2017； 27: 14-19.

77 Atala A, Bauer SB, Soker S, Yoo JJ, Retik AB. Tissue-engineered autologous bladders for patients needing cystoplasty. Lancet 2006 ; 367: $1241-46$

78 Joseph DB, Borer JG, De Filippo RE, Hodges SJ, McLorie GA. Autologous cell seeded biodegradable scaffold for augmentation cystoplasty: phase II study in children and adolescents with spina bifida. J Urol 2014; 191: 1389-95.

79 Nerli RB, Patil SM, Hiremath MB, Reddy M. Yang-Monti' s catheterizable stoma in children. Nephrourol Mon 2013; 5: 801-05. 80 Grimsby GM, Menon V, Schlomer BJ, et al. Long-term outcomes of bladder neck reconstruction without augmentation cystoplasty in children. J Urol 2016; 195: 155-61.

81 Ruano R, Sananes N, Wilson C, et al. Fetal lower urinary tract obstruction: proposal for standardized multidisciplinary prenatal management based on disease severity. Ultrasound Obstet Gynecol 2016; 48: 476-82

82 Morris RK, Malin GL, Quinlan-Jones E, et al.

Percutaneous vesicoamniotic shunting versus conservative

management for fetal lower urinary tract obstruction (PLUT0) :

a randomised trial. Lancet 2013; 382: 1496-506.

83 Kurtz MP, Koh CJ, Jamail GA, et al. Factors associated with fetal shunt dislodgement in lower urinary tract obstruction. Prenat Diagn 2016; 36: 720-25.

84 Kilby MD, Morris, RK. Fetal therapy for the treatment of congenital bladder neck obstruction. Nat Rev Urol 2014; 11: 412-19.

85 Sananes N, Favre R, Koh CJ, et al. Urological fistulas after fetal cystoscopic laser ablation of posterior urethral valves: surgical technical aspects. Ultrasound Obstet Gynecol 2015; 45: 183-89.

86 Polzin WJ, Lim FY, Habli M, et al. Use of an amnioport to maintain amniotic fluid volume in fetuses with oligohydramnios secondary to lower urinary tract obstruction or fetal renal anomalies. Fetal Diagn Ther 2017; 41: 51-57.

87 Hennus PM, de Kort LM, Bosch JL, de Jong TP, van der Heijden GJ. A systematic review on the accuracy of diagnostic procedures for infravesical obstruction in boys. PLoS One 2014; 9: e85474

Berrocal T, Gaya F, Arjonilla A. Vesicoureteral reflux: can the urethra be adequately assessed by using contrast-enhanced voiding US of the bladder? Radiology 2005; 234: 235-41.

89 Hoag NA, MacNeily AE, Abdi H, Figueroa V, Afshar K.

VURD syndrome-does it really preserve long-term renal function?

J Urol 2014; 191 (5 suppl): 1523-26.

90 Mandal S, Goel A, Kumar M, et al. Use of holmium: YAG laser in posterior urethral valves. Another method of fulguration.

J Pediatr Urol 2013; 9: 1093-97.

91 Gupta RK, Shah HS, Jadhav V, et al. Urethral ratio on voiding cystourethrogram: a comparative method to assess success of posterior urethral valve ablation. J Pediatr Urol 2010; 6: 32-36. 92 Smeulders N, Makin E, Desai D, et al. The predictive value of a repeat micturating cystourethrogram for remnant leaflets after primary endoscopic ablation of posterior urethral valves.

J Pediatr Urol 2011； 7: 203-08. 
93 Diamond DA, Ransley PG. Fogarty balloon catheter ablation of neonatal posterior urethral valves. J Urol 1987; 137: 1209-11.

94 Priti K, Rao KL, Menon P, et al. Posterior urethral valves: incidence and progress of vesicoureteric reflux after primary fulguration. Pediatr Surg Int 2004； 20: 136-39.

95 Koff SA, Mutabagani KH, Jayanthi VR. The valve bladder syndrome:

pathophysiology and treatment with nocturnal bladder emptying.

J Urol 2002; 167: 291-97.

96 Mitchell M. Persistent ureteral dilatation following valve resection. Dial Pediatr Urol 1982; 5: 8-10. 